\title{
REMOTELY MEASURING AND CONTROLLING SPECIFIC PARAMETERS OF A PV MODULE VIA AN RF LINK
}

\author{
Ntombizanele Maqache \\ Central University of Technology, Free State, (South Africa). \\ E-mail:nsolfafa@cut.ac.za ORCID: https://orcid.org/0000-0001-9457-1573 \\ Arthur James Swart \\ Central University of Technology, Free State, (South Africa). \\ E-mail: aswart@cut.ac.za ORCID: https://orcid.org/0000-0001-5906-2896
}

Recepción: 05/07/2021 Aceptación: 15/10/2021 Publicación: 14/12/2021

Citación sugerida:

Maqache, N., y Swart, A., J. (2021). Remotely measuring and controlling specific parameters of a PV module via an RF link. 3C Tecnología. Glosas de innovación aplicadas a la pyme, 10(4), 103-129. https://doi.org/10.17993/3ctecno/2021. v10n4e40.103-129 


\section{ABSTRACT}

The efficiency of PV modules is affected by a number of factors, including installation parameters and the module surface temperature. Installation parameters of PV modules focus primarily on the tilt and orientation angles, which have to be considered for optimum output power. Furthermore, the operating temperature of a PV module must be kept within certain limits, in order to obtain optimum electrical energy efficiency, depending on the module used. The purpose of this study was to measure the instantaneous surface temperature, voltage and current of a remote PV module in order to monitor its output power. An energy monitoring system was developed that received measurement data over an RF link. The PC transceiver of the system featured a CG1101 RF transceiver connected to the PG via an Arduino UNO, using a USB cable. The PV transceiver featured an Arduino Mega 2560, connected to a CG1101 RF transceiver to make the ST board, which contained all the sensors of the system. In addition, a graphical user interface was developed for sending and receiving measurements between the PG transceiver and the PV transceiver. The PV module voltage and current data was verified using a Fluke 115 DMM. The results showed a 4.9\% error percentage for voltage measurements and a 3.9\% error percentage for current measurements. Furthermore, a 29-day period of data showed the surface temperature to rise significantly higher than the ambient temperature during the day, indicating that there was considerable heating of the PV Module when there was solar radiation. The system could be used to compare the effect of cooling the PV module on the output power as the orientation angle is adjusted.

\section{KEYWORDS}

PV Module, Voltage, Current, Surface Temperature. 


\section{INTRODUCTION}

Fifty percent of the overall power consumption in the Information and Communication Technology (ICT) field is dedicated to telecommunication networks (Koutitas \& Demestichas, 2010). In fact, research has shown that a mobile base station uses an average of $36000 \mathrm{kWh}$ per year. The study included a sample of 6 mobile base stations in the center of Italy for shelter, room and outdoor types (Spagnuolo $e t$ al., 2015). The 2018 Telkom SA integrated report reflects $563055930 \mathrm{kWh}$ electricity consumption by the telecommunications giant in South Africa (Telkom, 2018). In addition, a forecast study estimates that communication technology will consume 51\% of the world's electricity in 2030 (Andrae \& Edler, 2015). This amplifies the need for more renewable and sustainable sources of electricity.

Photovoltaic (PV) modules are devices that convert solar energy directly into electrical energy without requiring mechanical energy and without producing greenhouse emissions. PV modules undergo performance characterization in Standard Test Conditions (STC) by primarily measuring its voltagecurrent (I-V) curve (Schwingsshackl et al., 2013). One study found that the operating temperature plays a key role in the process of PV conversion (Swapnil, Jatin, \& Bharath, 2013). In addition, the aforementioned authors concluded that there is a linear dependence of electrical efficiency, and thus output power, of a PV module with regard to the operating temperature of a module. PV's only convert $4-17 \%$ of the solar energy to electrical energy, the rest is converted to heat energy that is not used (Bai et al., 2016). Solar radiation and other weather parameters, have an effect on a PV module's operating temperature, and as such on its Cell Temperature (Tc) (Swapnil et al., 2013). Ambient temperature (Ta) is defined as the temperature of the air around the PV module (Bhattacharya, Chakraborty, \& Pal, 2014; Liu et al., 2015). The agreement across board is that the open-circuit voltage decreases considerably (about $2.3 \mathrm{mV} / \mathrm{C}$ ), while the short circuit current only decreases somewhat with increased PV module temperature (Bai et al., 2016).

As such, field measurements of the voltage and current of a PV module, allow more accurate data to be collected for practical operating conditions that differ slightly from the Standard Test Conditions, in 
order to optimize the overall system performance. Researchers used a simple approach of a digital multimeter to measure the voltage and current in a study that increased the efficiency of a PV module by $47 \%$ using cooling (Peng, Herfatmanesh, \& Liu, 2017). This approach is not an automated one and requires one to physically save the measurements from the multi-meter. A more complex combination of super capacitors, step-up and step-up converters were used to acquire voltage measurements in a study that monitored PV modules using wireless sensor networks (Prieto et al., 2014). The aforementioned study made use of ACS711 current sensors from Allegro, an 8-bit PIC microcontroller from Microchip for processing and XBee PRO 802.15.4 for communication. The study was successful in obtaining real-time measurements of PV modules for monitoring purposes. Alternatively, the voltage divider is a simpler and cheaper method that has been used in PV monitoring systems to obtain voltage measurements effectively, and in real-time (El Hammoumi et al., 2018; Kekre \& Gawre, 2017). A variety of sensors have also been used in PV monitoring systems to measure temperature (Atsu et al., 2020), which includes the LM35 and Pt-100 sensors. Alternatively, a thermographic camera can be used to measure the temperature distribution over the module's surface (Nedelchev \& Zhivomirov, 2020), although it is again a manual approach. An automatic PV module monitoring system was designed in Spain with a complex control unit that connects a PV system physically to a computer to control the measuring circuit (Ortega et al., 2018). This design proved to be both complex and expensive.

The monitoring system presented in this paper aims to be both a non-complex and cost-effective solution as it eliminates physically connecting the PV module and the data recording system. The design and development of a cost-effective remote measuring and monitoring system that will record the voltage, current and surface temperature of a remote PV module via a Radio-Frequency (RF) link is contained herein. Measuring these remote parameters instantaneously will allow effective monitoring in order to maintain a high output power. The sections that follow will explore the sensing technologies used to obtain measurements as well as the results obtained over a given period. The communication technology 
used to send and receive data to a remote PV module will also be presented. Lastly, this paper will show the user interface used for the synergy of all the system parameters and controls.

\section{SYSTEM DESIGN AND PRACTICAL SET-UP}

The block diagram contained in Figure 1 shows the overall setup of the system design for remotely measuring current, voltage and temperature. Block 1 is the Master Transceiver (MT) where the user can see the real-time sensor data displayed on the PG that is sent from block 2 which is the Slave Transceiver (ST) responsible for collecting data using a microcontroller. Block 3 shows all the parameters of the PV module that are collected by the microcontroller.

When measurements are acquired from the PV module, there needs to be a method of processing and saving the data for monitoring or analysis. Hence the need for a microcontroller where three options were considered. Firstly, Rasberry Pi 3 model B+ is the latest release in the Rasberry Pi 3 range that makes use of the Broadcom BCM2837B0 processor with $1.4 \mathrm{GHz}$ operating speed. Although a RAM of $1 \mathrm{~Gb}$ makes it attractive, the drawback is that this board requires an external ADC, which will contribute to the cost and complexity of the design (Rasberry Pi, 2018). Secondly, the BeagleBone Black incorporates the TI Sitara AM3358 processor at the operating speed of $1 \mathrm{GHz}$ and 512Mb of RAM with six analog input pins. This option is more expensive and more complex to implement. Lastly, the Arduino Uno is based on the ATmega328 microcontroller, has 16 digital input / output pins, six analog inputs and a USB connection. It was chosen for designing a data logger for a PV system for its simplicity and modularity, in comparison with other boards (Arduino, 2018; Fuentes et al., 2014). The Arduino platforms allow for easy learning and adaptation, because it is open ware, as such there are modules and libraries readily available on the internet. 


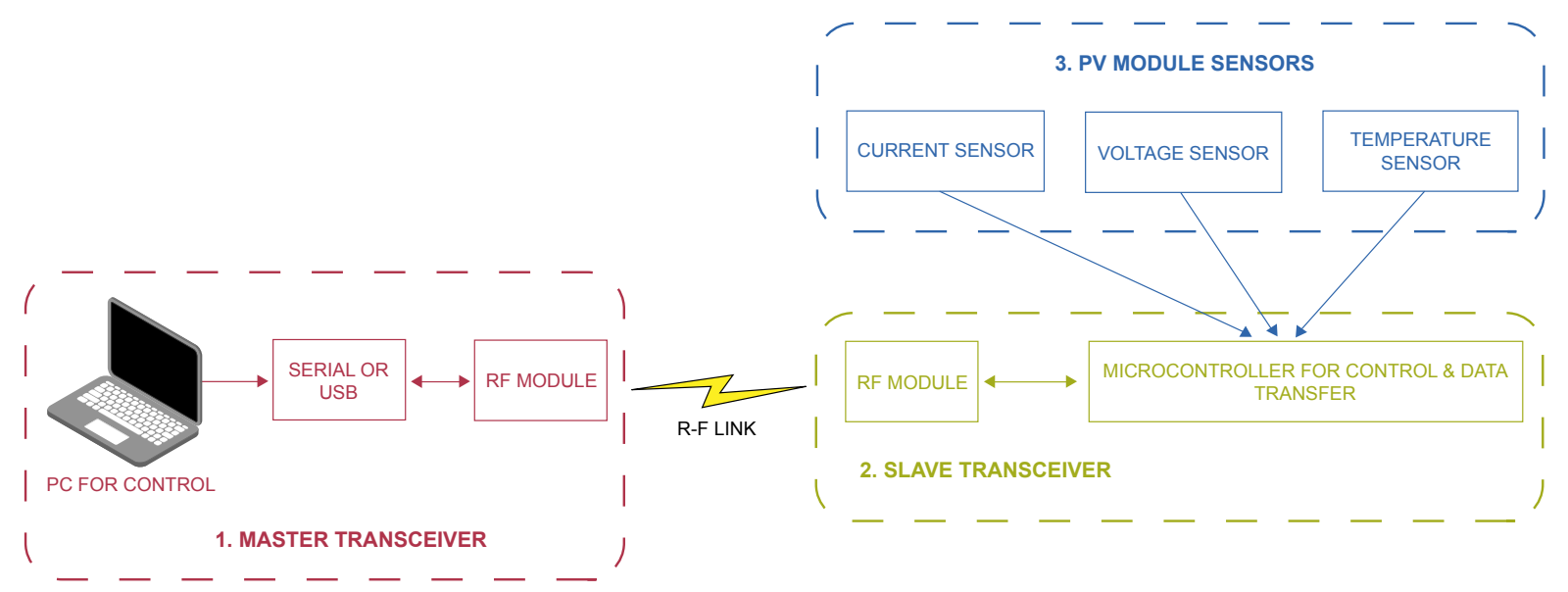

Figure 1. Block diagram of the practical set-up.

Source: own elaboration.

Wireless technology (the RF Link in Figure 1) is used to transfer information between two or more points that are not physically connected to form wireless communication. Wireless technologies prove useful when it comes to accessing data from a remote site that is without electricity or telephone lines. Wireless communication can be achieved through either radio frequency, microwave or infrared. An RF transceiver module is an integrated circuit that transmits and receives radio signals on a given carrier frequency (433 MHz as an example). The CG1101 is an example of such a module. It has different communication modes that can be changed by command. In addition, it can transmit over distances of up to $500 \mathrm{~m}$ in open-air line of sight without any obstacles to absorb radio signals at a rate of about 600 kBps (Texas Instruments, 2018). The usefulness of RF modules in remote-sensing and control is widely accepted in many industries. In wireless communication, power consumption is increased with bigger communication distances. It is therefore required for wireless communication to consume minimal power for remote sites. This is why RF modules are also widely used in renewable energy system monitoring, as they have very low power consumption and also for their low-cost and wide open-air range capabilities 
(Kama et al., 2017). Added to these advantages, they eliminate the need for physical wiring between two points that can complicate the installation of the energy monitoring system.

PV module sensors of Figure 1 include the voltage divider, the ACS712 and the DHT11. The voltage divider is commonly used in PV data acquisition to obtain higher voltage measurements because it is non-complex and inexpensive. The voltage divider is designed such that its output is proportional to the input voltage and small enough to be processed by a microprocessor. For current measurements, Hall Effect current transducers (LEM LA100-P, LA55p, Honeywell Microswitch CSLA1CF) have been used to measure current for more complex PV applications (Belmili et al., 2010; Tina \& Grasso, 2014). The ACS712 has a precise proportional voltage provided by the low-offset, chopper-stabilized BiCMOS Hall IC, which is programmed for accuracy after packaging (Allegro Microsystems, 2006). The DHT11 humidity and temperature sensor is a semiconductor thermometer device that is made up of a resistive type humidity measurement component and an NTG temperature measurement component. It connects to a microcontroller for excellent quality, fast response, anti-interference ability and cost-effectiveness (D-Robotics, 2010). Their digital output can be connected to a microcontroller without complex circuitry, which contributes to the overall cost of the setup.

\subsection{THE GRAPHICAL USER INTERFACE (GUI)}

The graphical user interface is used to connect the user (Master Transceiver) to the PV module sensors (Slave Transceiver) using the RF link as shown in Figure 1. The GUI is designed using Visual Studio C\# with its purpose being for the end user of the system to visually see the data being sent from the ST or to interact with the system. Figure 2 shows the GUI with numbered items that are used to illustrate its functionality. The numbered items of the GUI are presented below with their functionality explained: 
1. Serial port settings to be selected by the user.

The serial port settings are obtained from combo boxes where the user selects the appropriate port name, baud rate, parity, stop bits and handshake.

2. Tabs that can be selected to view different data representations.

The data grid sorts the data received into the 7 relative columns with the last column being the time the measurements are received. The columns are named after the measurement reading they collect; PV voltage, Battery voltage, Load voltage, PV current, Battery current, Load current and Temperature. The data grid is displayed in the second tab of the GUI that is named "Live table". The third tab displays the chart representation of all the PV measurements, this being the PV voltage vs time, PV current vs time, Temperature vs time and Power vs time. Tab four and five show the same charts (except for temperature) for the battery and the load.

3. The button used to turn on the water sprayer for 5 seconds at the PV module.

This functionality could be used to control the water sprayer used for cooling the PV module when the surface temperature gets too high. When clicked, a signal is sent to the ST to activate for 5 seconds.

4. Buttons used to move the PV module either left or right by $10^{\circ}$ to adjust the orientation angle. The orientation angle could be varied using these buttons to achieve the desired angle. When these are clicked, a signal is sent to the ST to either extend or retract the actuator for a set period. 


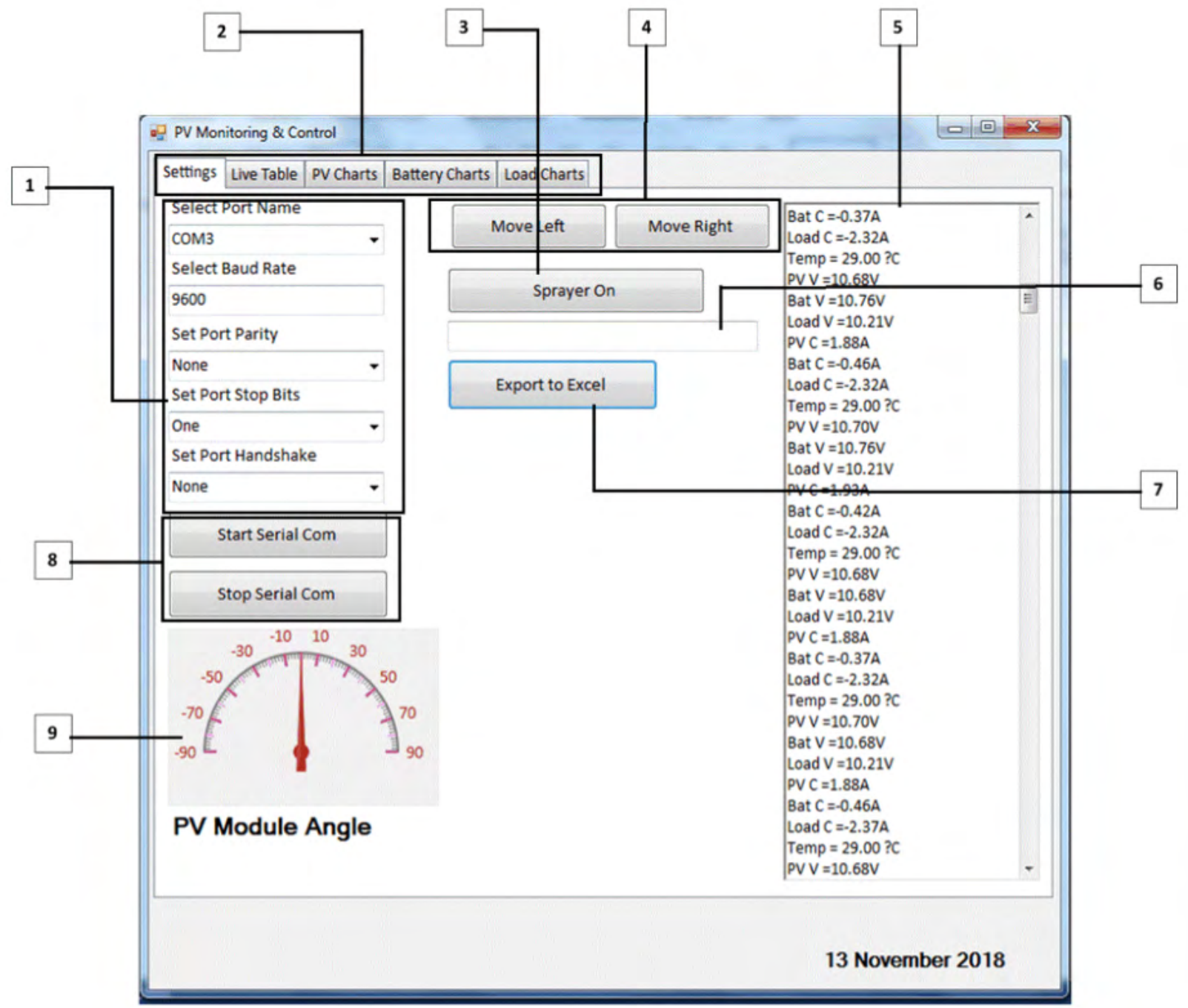

Figure 2. User interface.

Source: own elaboration. 
5. Displays the real time measurements as they are received from the ST.

Measurements received by the MT from the ST are displayed in this text box in rea-time and loaded in the live table in the GUI.

6. Displays commands that are sent to the ST when buttons are clicked for the water sprayer and actuator.

This enables the user to see the status of the control commands to avoid unwanted repetition.

7. The button that is used to send data to an excel sheet and save as a predetermined file name.

The export to Excel method is called after every 100 rows and when the user clicks the button. When this is done, an Excel file is created named "ExportedFromDatGrid". The file is saved to the path specified that includes the day's date and binary time format which ensures a unique file name each time.

8. Buttons used to either start or stop serial communication between the MT and the ST.

Communication between the MT and the ST is initiated or terminated by these buttons, giving the user control over when to start recording measurements.

9. Displays the real time orientation angle of the PV module.

This gauge displays the orientation angle of the PV module as it is adjusted either left or right by the control commands.

\subsection{MASTER TRANSCEIVER BOARD}

The GUI uses the MT to interface the user at the PC with the measurement system at the PV module (ST). The MT is responsible for receiving measurements and sending commands over the RF-link as well as saving it on the PC. The MT board in Figure 3 is designed to plug into the Arduino UNO board that connects to the PC using the USB port. 


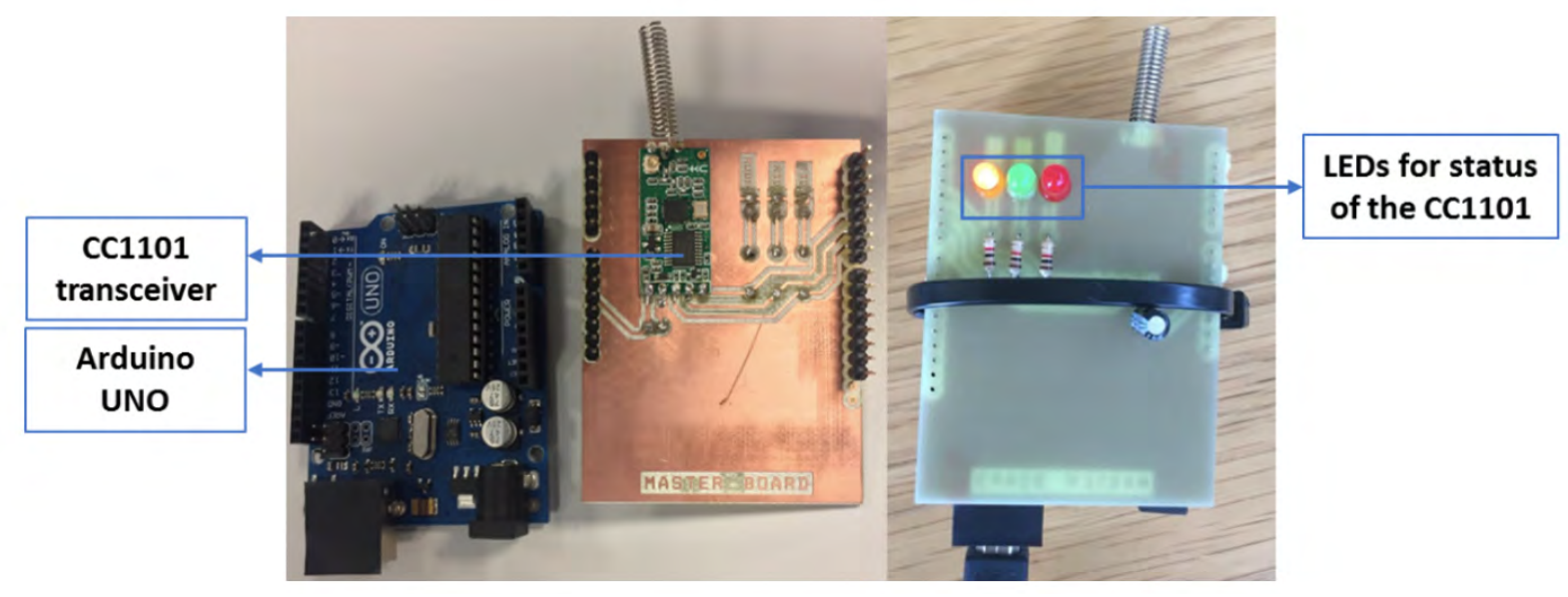

Figure 3. Arduino and Master Transceiver.

Source: own elaboration.

It houses the CG1101 transceiver for wireless communication with the three LEDs indicating the mode of the transceiver device; red being idle, green being receive data and yellow being transmit data. The microcontroller was only used for the wireless communication; hence the Arduino Uno was chosen because not many output pins were required for this function and for its simplicity, low cost and modularity.

\subsection{SLAVE TRANSCEIVER BOARD}

The MT receives measurements of the PV module from the ST to display on the GUI. The ST board (Figure 4) houses the second CG1 101 and the three sensors on the PV module side. The Arduino Mega that is used as the microcontroller has the same processing speed as the Arduino Uno with more RAM $(8 \mathrm{~Kb})$ and $\mathrm{I} / \mathrm{O}(54)$ pins allowing more data to be processed in and out by the microcontroller. This transceiver board was developed as a shield for the microcontroller and connects it to the voltage, 
current and temperature sensors that obtain data from the PV module, battery and the load. This data is transmitted to the MT board.

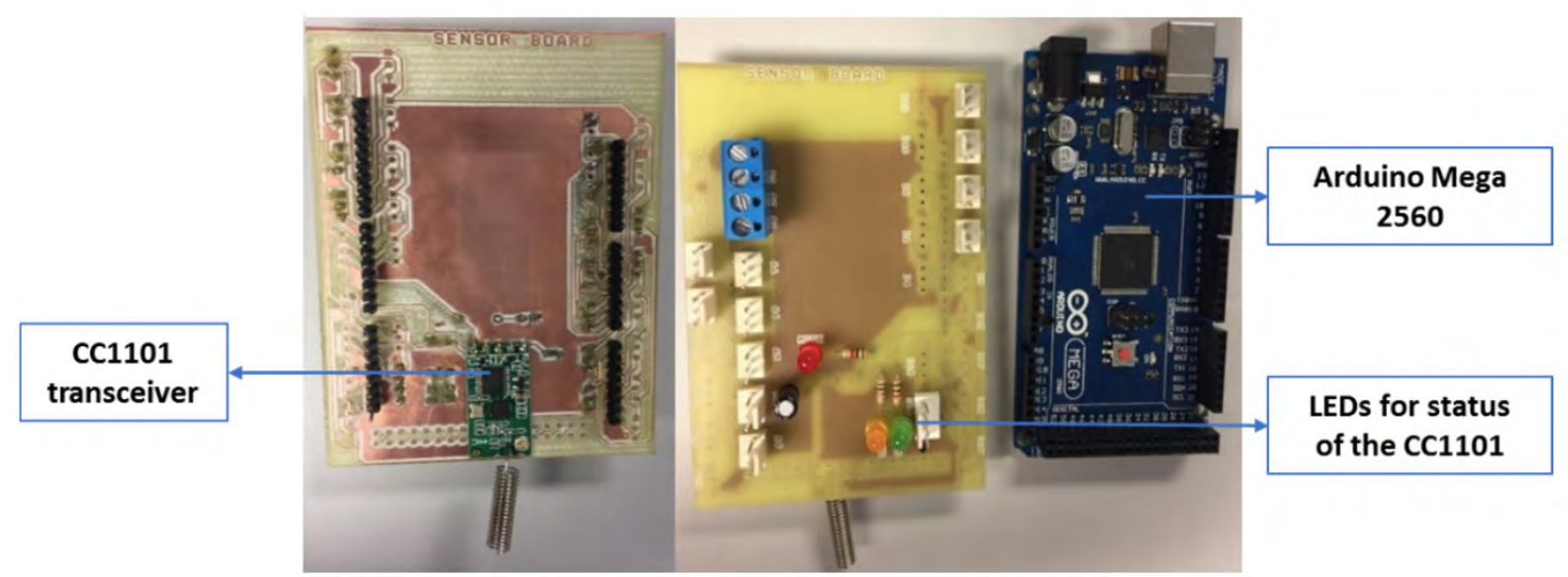

Figure 4. Slave Transceiver Board.

Source: own elaboration.

The measurements from the sensors are sent to the serial port of the Arduino Mega 2560. The transmitting device, CG1101 transceiver RX and TX pins are connected to this Arduino's serial port 0 at pin 0 and 1 respectively. This means that the measurements that are sent to the serial port of the Arduino Mega 2560 are then transmitted by the CG1101 transceiver. When the Arduino Mega 2560 is connected to a PC using a USB cable, terminal software can be used to display these measurements on the serial port of the PC through the USB port. This feature might be used in environments that are not remote and do not require wireless transmission.

\subsection{SLAVE TRANSCEIVER SENSORS}

Measurements are obtained using sensors connected on the ST board; they were designed to fit onto the Arduino Mega 2560 which processes the signals. Voltage dividers are used to obtain higher voltage 
measurements in a noncomplex and inexpensive manner, and are commonly used in PV data acquisition (Tina \& Grasso, 2014). The voltage divider is designed such that its output $\left(V_{\text {OUT }}\right)$ is proportional to the input voltage $\left(V_{P V}\right)$ and small enough to be processed by a microprocessor. The output of the voltage divider is calculated by:

$$
V_{\text {out }}=\left(\frac{10 K \Omega}{47 \mathrm{~K} \Omega+10 \mathrm{~K} \Omega}\right) \times V_{P V}
$$

Where $V_{P V}$ is the voltage from the PV modules 4 x SD ECO PLUS $10 \mathrm{~W}$ PV modules connected in parallel). The open circuit voltage $\left(V_{O C}\right)$ for these is $20.8 \mathrm{~V}$ and the short circuit current $\left(I_{S C}\right)$ is $0.78 \mathrm{~A}$. The Arduino Mega 2560 analog input pins can measure voltages from ground to $5 \mathrm{~V}$, supplying these pins with anything more will damage them. As such, voltage dividers are used to sense the voltages of the PV module, battery and load, while fuses are used to protect the circuitry against any unwanted currents.

$V_{\text {OUT }}$ from these sensors is connected to the 3 analog pins of the Arduino Mega 2560 respectively. The microcontroller then uses a programmed algorithm to process the voltage divider output and convert it to a relative voltage.

Hall-effect current transducers have been used to measure current for more complex PV applications (Tina \& Grasso, 2014). The Allegro ACS712 sensor comprises a precise, low-offset, linear Hall sensor circuit with a hall element. A precise, proportional voltage is provided by the low-offset, chopperstabilized BiCMOS Hall IC, which is programmed for accuracy after packaging (Allegro Microsystems, 2006). The analog input of the Arduino from the sensor is used in the formula below in order to arrive to the current reading:

$$
I=\frac{\left(\frac{\text { PinRead }}{1023} \times 5000\right)-2500}{100}
$$

PinRead is the analog input, the 1023 is the 10-bit resolution of the ADC and the 5000 is the reference voltage in $\mathrm{mV}$. Because the offset of the current sensor is $2500 \mathrm{mV}$, it must be subtracted to arrive to the actual current in $\mathrm{mA}$. 
The DHT1 1 humidity and temperature sensor is a semiconductor thermometer device that is made up of a resistive type humidity measurement component and an NTC (Negative Temperature Coefficient) temperature measurement component. It connects to a microcontroller for excellent quality, fast response, anti-interference ability and cost-effectiveness (Gay, 2018). This digital sensor was used to develop a humidity and temperature remote sensing system that was cost-effective and fast for real-time operations (Randhir \& Karhe, 2015). It can measure temperatures of up to $50^{\circ} \mathrm{C}$ with the accuracy of $+-2^{\circ} \mathrm{C}$. The temperature sensor also connects to the ST board and gives real time temperature of the PV module's surface in Degrees Celsius $\left({ }^{\circ} \mathrm{C}\right)$. As established in the previous section, the surface temperature of the PV module is important to its efficiency.

\section{METHODOLOGY}

The experimental set-up included the PV module, battery and 12 V LED flood light connected to a programmable solar charge controller on a balcony of a building at the Central University of Technology, Free State. The site is located in the city of Bloemfontein, South Africa where the latitude is -29.087 and the longitude is 26.154. The PV voltage and current were measured between the charge controller and the PV module. The battery voltage and current measurements were acquired between the battery and the charge controller. The temperature is a measurement of the PV module surface temperature and was obtained from the sensor that was attached to the back of the PV module. Measurement data was acquired every 100 seconds from the ST via RF using the MT and saved to an MS Excel sheet using the GUI. The data in MS Excel was analysed using Pivot Tables and then represented using line graphs. The results of the PV voltage and current are presented below for a cloudy and sunny day in September, as well as surface temperature measurements for a 29 day period in July and August of 2019. July and August are winter months where temperatures have been seen to go below $0^{\circ} \mathrm{C}$ whereas September is spring where warmer days can be found. 


\section{RESULTS}

\subsection{RESULTS OF THE PV MODULE VOLTAGE AND CURRENT MEASUREMENTS VERIFIED BY DMM}

Experimental results are presented here for different weather conditions with the load connected. The SD eco plus $10 \mathrm{~W}$ PV module was used with the rated parameters shown in Table 1 that are obtained under Standard Testing Conditions (STC). Four of these modules were connected in parallel, giving the expected parameters of Table 1.

Table 1. PV module parameters.

\begin{tabular}{|c|c|}
\hline STC parameters for one PV module & STC parameters for four PV modules in parallel \\
\hline $\mathrm{I}_{\mathrm{mp}}$ (maximum power current) $=0.61 \mathrm{~A}$ & $\mathrm{I}_{\mathrm{mp}}=2.44 \mathrm{~A}$ \\
\hline $\mathrm{V}_{\mathrm{mp}}$ (maximum power voltage) $=16.5 \mathrm{~V}$ & $\mathrm{~V}_{\mathrm{mp}}=16.5 \mathrm{~V}$ \\
\hline $\mathrm{I}_{\mathrm{sc}}$ (short circuit current) $=0.78 \mathrm{~A}$ & $\mathrm{I}_{\mathrm{sc}}=3.12 \mathrm{~A}$ \\
\hline $\mathrm{V}_{\mathrm{oc}}$ (open circuit voltage) $=20.8 \mathrm{~V}$ & $\mathrm{~V}_{\mathrm{oc}}=20.8 \mathrm{~V}$ \\
\hline Peak Power $=10 \mathrm{~W}$ & Peak Power $=40 \mathrm{~W}$ \\
\hline
\end{tabular}

Source: own elaboration.

A Fluke 115 digital multimeter (DMM) was used to verify the voltage and current measurements from the voltage divider and ACS712 sensors on the PV module transceiver. In Figure 5, a spreadsheet of sensor measurements obtained from the PV module transceiver for 27 September 2019 is observed, where a voltage and current reading was compared to a DMM voltage and current reading.

The accuracy of the voltage and current sensor measurements was evaluated by calculating the percentage error between the sensor measurements and the DMM readings as follows: 


$$
\% \text { error }=\frac{\text { sensor reading }-D M M \text { reading }}{D M M \text { reading }} \times 100
$$

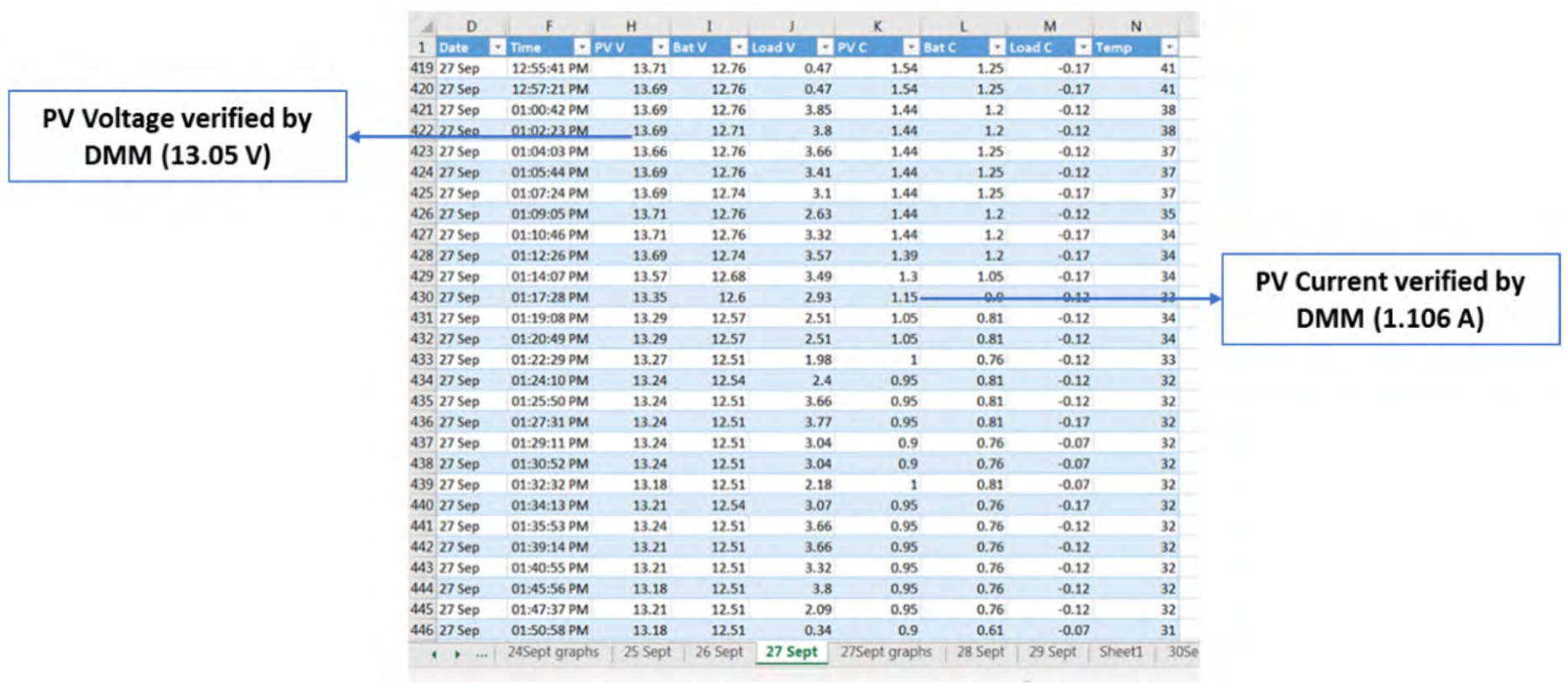

Figure 5. PV voltage and current measurements verified using a DMM.

Source: own elaboration.

The PV voltage of $13.69 \mathrm{~V}$ from the PV module transceiver and 13.05 V from the DMM were used in equation 3 to give an error percentage of $4.9 \%$. In addition, the error percentage for the current reading was calculated using the PV current of 1.15 A from the PV module transceiver and 1.106 A from the DMM, giving a value of $3.9 \%$. A percentage error of between $-10 \%$ and $+10 \%$ has been found to be acceptable for these type of measurements (Ertekin \& Yaldiz, 2000). 


\subsection{RESULTS OF THE PRACTICAL SETUP MEASUREMENTS OF PV VOLTAGE AND CURRENT OVER SEVEN DAYS}

Measurement data was acquired every 100 seconds from the ST via RF using the MT continually for a period of seven days. The data stored by the GUI was processed using pivot tables and summarized to hourly maximums. The daily PV voltage curve for the period above is presented in Figure 6 where the voltage can be observed to be higher for the days where the load is switched off. The PV module terminal voltage reaches $13.8 \mathrm{~V}$ when the load is on. When the load is switched off by the solar charge controller, the battery then acts as a load and draws current from the PV module. The terminal voltage the PV module, in this case, reaches is $15.44 \mathrm{~V}$ when the LED load is switched off and the battery is charging. Both values of PV voltage are less than the rated maximum power voltage of $16.5 \mathrm{~V}$, which indicates that the process of measuring is satisfactory. Hourly maximum measurements of PV voltage for 24 September show a maximum of $12.76 \mathrm{~V}$ at $12 \mathrm{pm}$. Hourly maximum PV voltage for 27 September show a maximum of $13.8 \mathrm{~V}$ at $10 \mathrm{am}$. The maximum terminal voltage of the PV module is less than the rated maximum power voltage throughout the presented period.

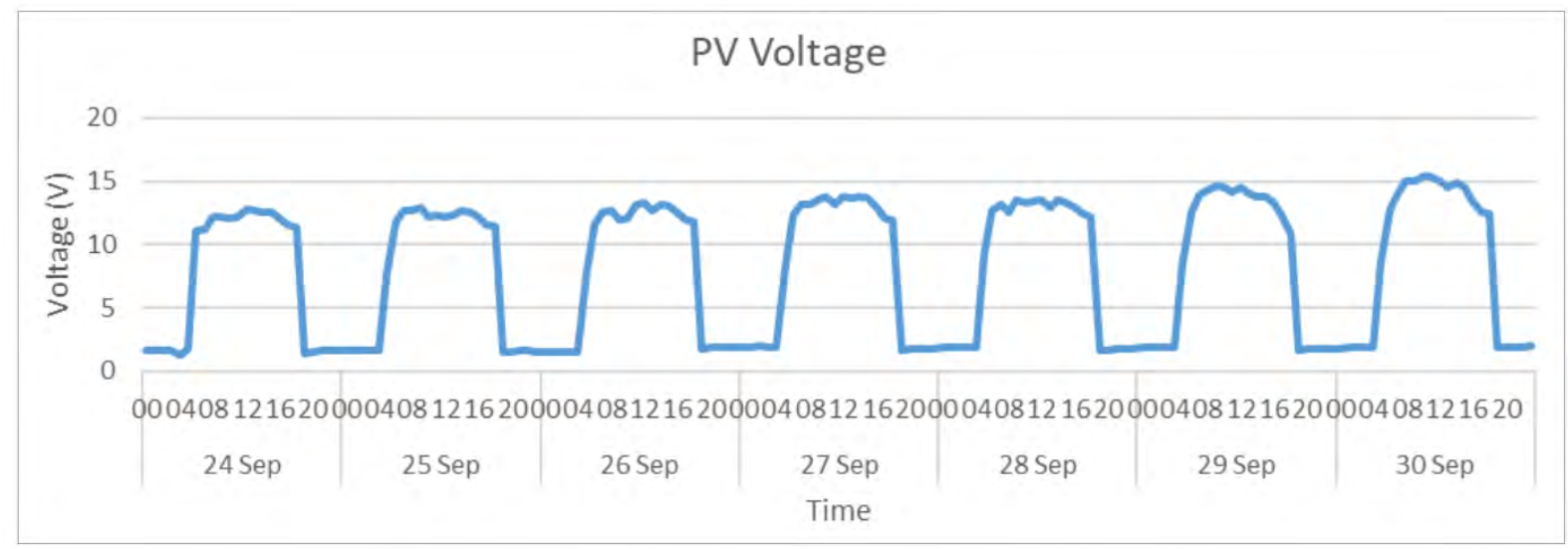

Figure 6. Hourly maximum of PV voltage from 24 to 30 September 2019.

Source: own elaboration. 
Daily maximum PV current is presented in Figure 7 from 24 to 30 September. The diagram shows that the maximum current recorded was less than the rated $\mathrm{I}_{\mathrm{mp}}=2.44 \mathrm{~A}$ for the said period. The highest maximum PV current is 2.43 A on 28 September and the lowest recorded maximum PV current 1.98 A on 29 September.

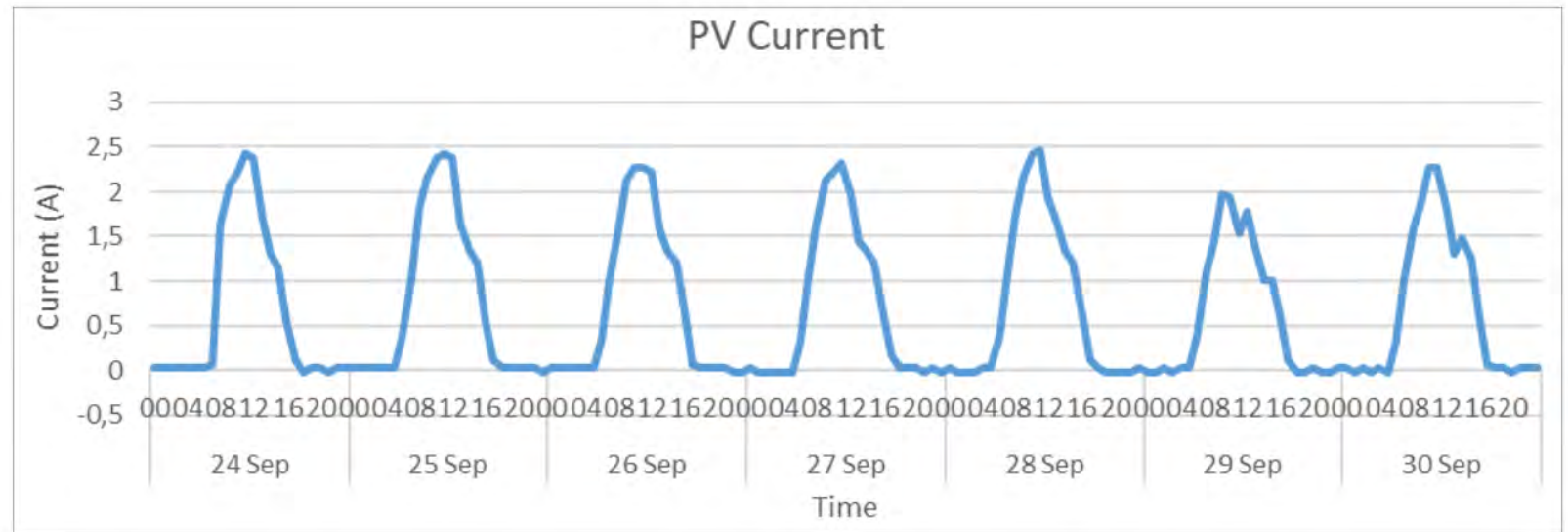

Figure 7. Hourly maximum of PV current from 24 to 30 September 2019.

Source: own elaboration.

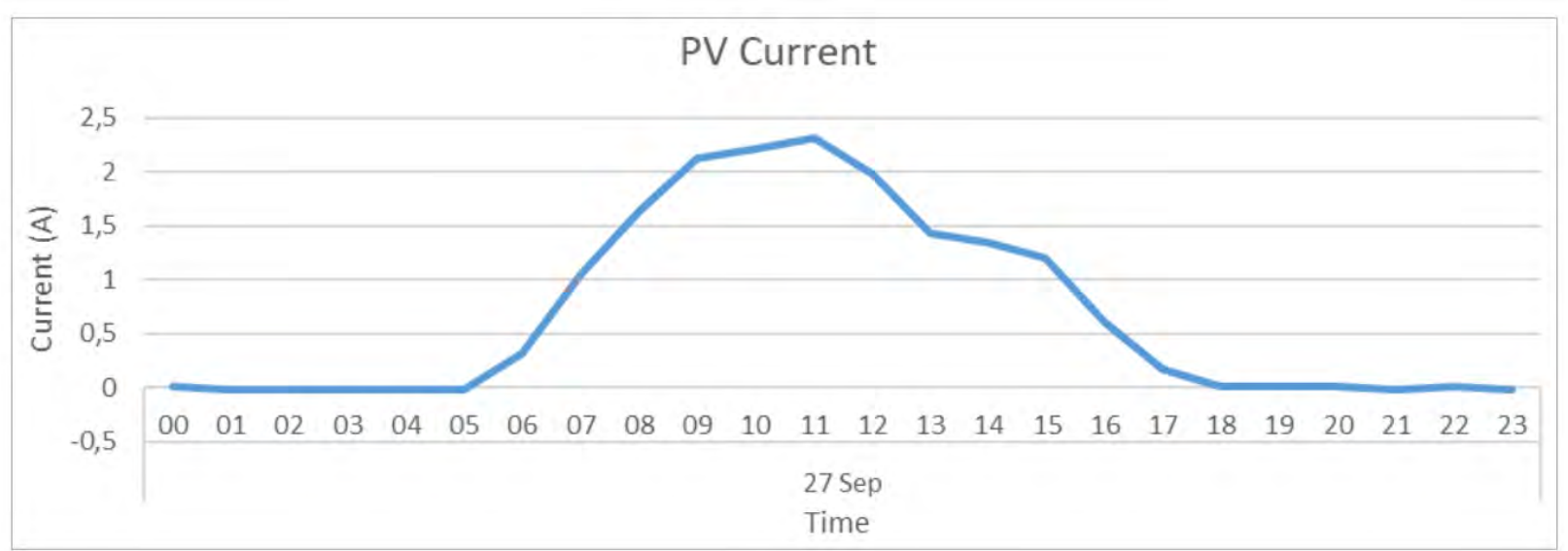

Figure 8. Hourly maximum of PV current for 27 September 2019 (Sunny day).

Source: own elaboration. 


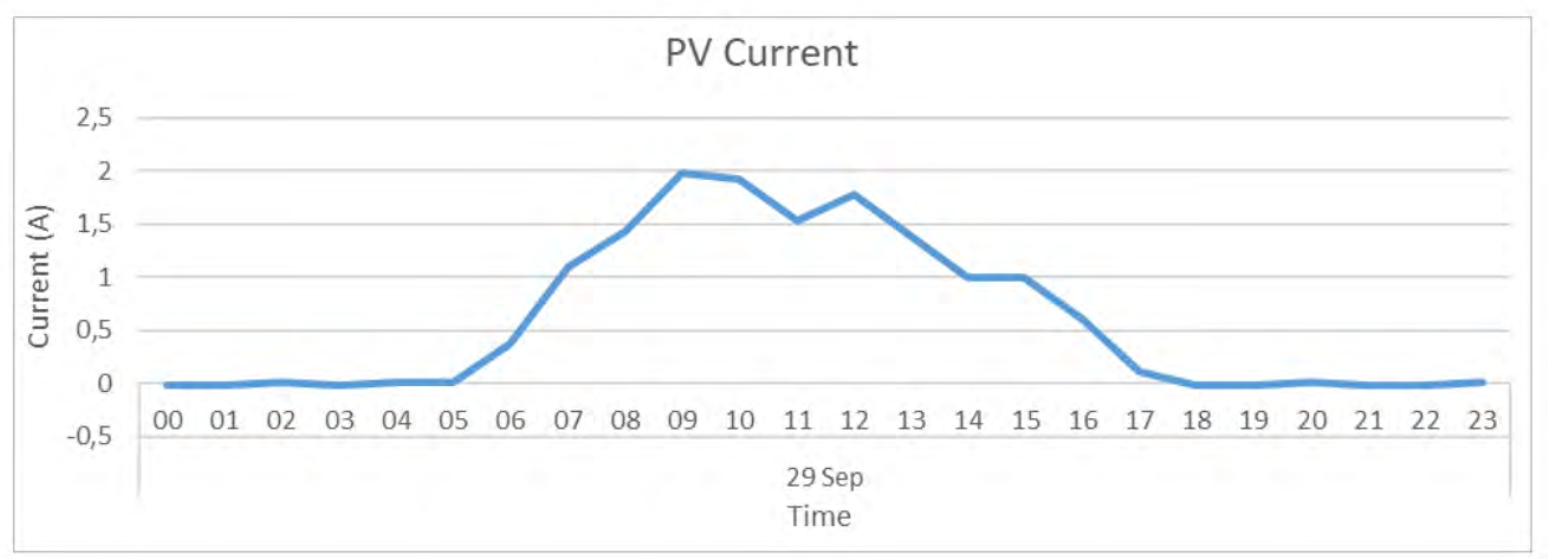

Figure 9. Hourly maximum of PV current for 29 September 2019 (Cloudy day).

Source: own elaboration.

A closer look at the daily performance shows hourly maximum PV currents for a sunny day on site (Figure 8) and for a cloudy day (Figure 9). The measurements reflect the maximum current drawn from the PV module as 2.32 A at 11 am for the sunny day and $1.98 \mathrm{~A}$ at 11 am for a cloudy day. Both currents are less than 2.44 A maximum power current of Table 1, suggesting that the measurement process is satisfactory.

\subsection{RESULTS OF THE PV MODULE SURFACE TEMPERATURE VERIFIED BY DMM}

The measurements from the DHT11 sensor were verified using the Fluke 179 Digital Multimeter (DMM). The sensor measurement of $34^{\circ} \mathrm{C}$ in Figure 8 was judged against the DMM reading of $33.8^{\circ} \mathrm{C}$ and a percentage error calculated, using equation 3 arriving at an error percentage of $0.59 \%$, indicating that the measurements from the sensor are acceptable. 


\begin{tabular}{|c|c|c|c|c|c|c|c|c|c|c|c|c|}
\hline \multirow{3}{*}{$\frac{4}{419}$} & D & $\mathrm{F}$ & \multicolumn{2}{|r|}{ H } & 1 & J & K & L & M & \multicolumn{2}{|l|}{$\mathrm{N}$} & \\
\hline & Date & - Time & - PVV & $1-1$ & Bat V & Load V - & - BatC & -1 & Load C $\quad-$ & Temp & - & \\
\hline & 27 Sep & $12: 55: 41$ & PM & 13.71 & 12.76 & $5 \quad 0.47$ & 1.54 & 1.25 & -0.17 & & 41 & \\
\hline 420 & 27 Sep & $12: 57: 21$ & PM & 13.69 & 12.76 & 0.47 & 1.54 & 1.25 & -0.17 & & 41 & \\
\hline 421 & $27 \mathrm{sep}$ & $01: 00: 42$ & & 13.69 & 12.76 & 3.85 & 1.44 & 1.2 & -0.12 & & 38 & \\
\hline 422 & $27 \mathrm{Sep}$ & 01:02:23 & & 13.69 & 12.71 & 3.8 & 1.44 & 1.2 & -0.12 & & 38 & \\
\hline 423 & $27 \mathrm{Sep}$ & 01:04:03 & & 13.66 & 12.76 & 3.66 & 1.44 & 1.25 & -0.12 & & 37 & \\
\hline 424 & $27 \mathrm{Sep}$ & $01: 05: 44$ & PM & 13.69 & 12.76 & 3.41 & 1.44 & 1.25 & -0.12 & & 37 & \\
\hline 425 & 27 Sep & 01:07:24 & PM & 13.69 & 12.74 & 3.1 & 1.44 & 1.25 & -0.17 & & 37 & \\
\hline 426 & 27 Sep & 01:09:05 & PM & 13.71 & 12.76 & 2.63 & 1.44 & 1.2 & -0.12 & & 35 & \\
\hline 427 & 27 Sep & 01:10:46 & PM & 13.71 & 12.76 & 3.32 & 1.44 & 1.2 & -0.17 & & 34 & PV Surface Temperature \\
\hline 428 & 27 Sep & 01:12:26 & PM & 13.69 & 12.74 & 3.57 & 1.39 & 1.2 & -0.17 & & 34 & - \\
\hline 429 & $27 \mathrm{Sep}$ & 01:14:07 & PM & 13.57 & 12.68 & 3.49 & 1.3 & 1.05 & -0.17 & & 34 & verified by DMM \\
\hline 430 & 27 Sep & 01:17:28 & PM & 13.35 & 12.6 & 2.93 & 1.15 & 0.9 & -0.12 & & 33 & $\left(238^{\circ} \mathrm{C}\right)$ \\
\hline 431 & 27 Sep & 01:19:08 & PM & 13.29 & 12.57 & 2.51 & 1.05 & 0.81 & -0.12 & & 34 & $\left(33.8^{\circ} \mathrm{C}\right)$ \\
\hline 432 & 27 Sep & $01: 20: 49$ & PM & 13.29 & 12.57 & 2.51 & 1.05 & 0.81 & -0.12 & & 34 & \\
\hline 433 & $27 \mathrm{Sep}$ & 01:22:29 & PM & 13.27 & 12.51 & 1.98 & 1 & 0.76 & -0.12 & & 33 & \\
\hline 434 & $27 \mathrm{Sep}$ & $01: 24: 10$ & PM & 13.24 & 12.54 & 2.4 & 0.95 & 0.81 & -0.12 & & 32 & \\
\hline 435 & 27 Sep & $01: 25: 50$ & & 13.24 & 12.51 & 3.66 & 0.95 & 0.81 & -0.12 & & 32 & \\
\hline 436 & 27 Sep & 01:27:31 & PM & 13.24 & 12.51 & 3.77 & 0.95 & 0.81 & -0.17 & & 32 & \\
\hline 437 & $27 \mathrm{sep}$ & 01:29:11 & PM & 13.24 & 12.51 & 3.04 & 0.9 & 0.76 & -0.07 & & 32 & \\
\hline 438 & 27 Sep & $01: 30: 52$ & PM & 13.24 & 12.51 & 3.04 & 0.9 & 0.76 & -0.07 & & 32 & \\
\hline 439 & $27 \mathrm{Sep}$ & $01: 32: 32$ & PM & 13.18 & 12.51 & 2.18 & 1 & 0.81 & -0.07 & & 32 & \\
\hline 440 & 27 Sep & $01: 34: 13$ & PM & 13.21 & 12.54 & 3.07 & 0.95 & 0.76 & -0.17 & & 32 & \\
\hline 441 & $27 \mathrm{Sep}$ & $01: 35: 53$ & PM & 13.24 & 12.51 & 3.66 & 0.95 & 0.76 & -0.12 & & 32 & \\
\hline 442 & $27 \mathrm{Sep}$ & 01:39:14 & PM & 13.21 & 12.51 & 3.66 & 0.95 & 0.76 & -0.12 & & 32 & \\
\hline 443 & 27 Sep & $01: 40: 55$ & PM & 13.21 & 12.51 & 3.32 & 0.95 & 0.76 & -0.12 & & 32 & \\
\hline 444 & $27 \mathrm{Sep}$ & $01: 45: 56$ & & 13.18 & 12.51 & 3.8 & 0.95 & 0.76 & -0.12 & & 32 & \\
\hline 445 & $27 \mathrm{Sep}$ & $01: 47: 37$ & & 13.21 & 12.51 & 2.09 & 0.95 & 0.76 & -0.12 & & 32 & \\
\hline 446 & 27 Sep & $01: 50: 58$ & PM & 13.18 & 12.51 & 0.34 & 0.9 & 0.61 & -0.07 & & 31 & \\
\hline , & +,$\ldots$ & 24 Sept g & raphs & 25 Sept & $26 \mathrm{Sept}$ & 27 Sept & 27Sept graphs & 28 Sept & 29 Sept & Sheet1 & $305 \mathrm{e}$ & \\
\hline
\end{tabular}

Figure 10. PV module surface temperature measurements verified by DMM.

Source: own elaboration.

\subsection{RESULTS OF THE PRACTICAL SETUP MEASUREMENT OF PV SURFACE TEMPERATURE OVER 29 DAYS}

Figure 11 reflects hourly maximum PV surface temperature measurements for a cloudy day. The maximum surface temperature for 29 September 2019 is recorded as $39^{\circ} \mathrm{C}$ at 09:00 am. Figure 12 reflects hourly maximum PV surface temperature measurements for a sunny day. The maximum surface temperature for 27 September 2019 is recorded as $54^{\circ} \mathrm{C}$ at 12:00 pm. 


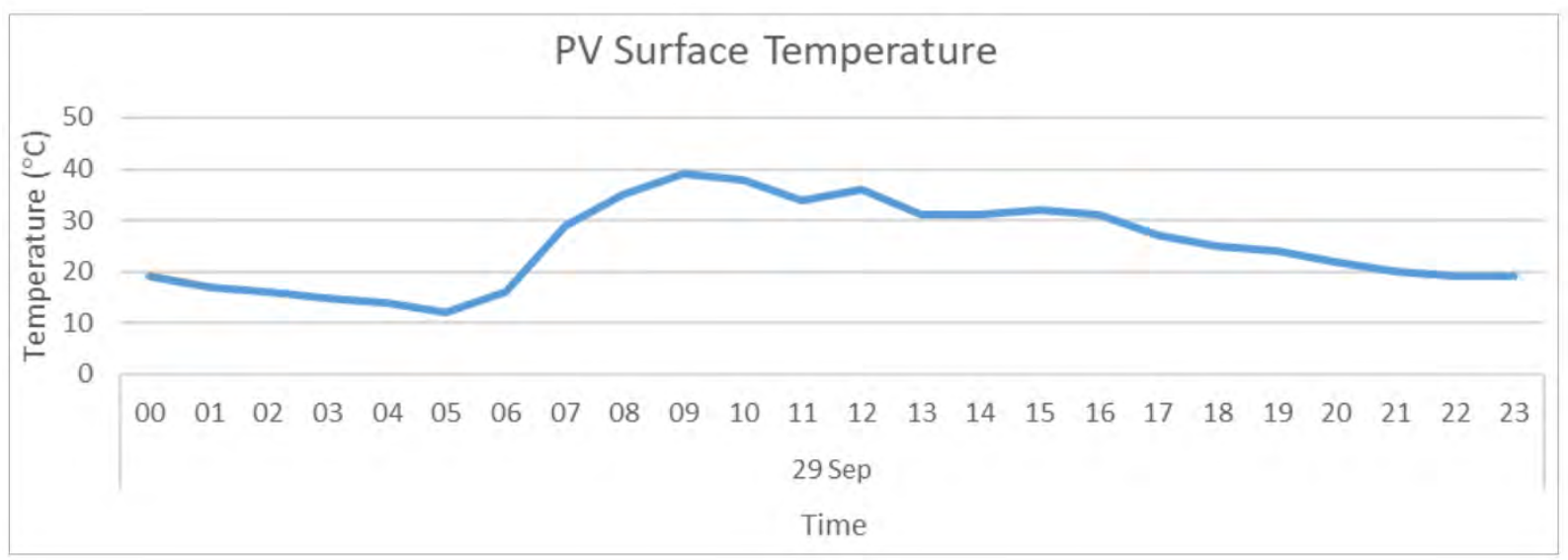

Figure 11. Hourly maximum of PV module surface temperature for 29 September 2019 (Cloudy day).

Source: own elaboration.

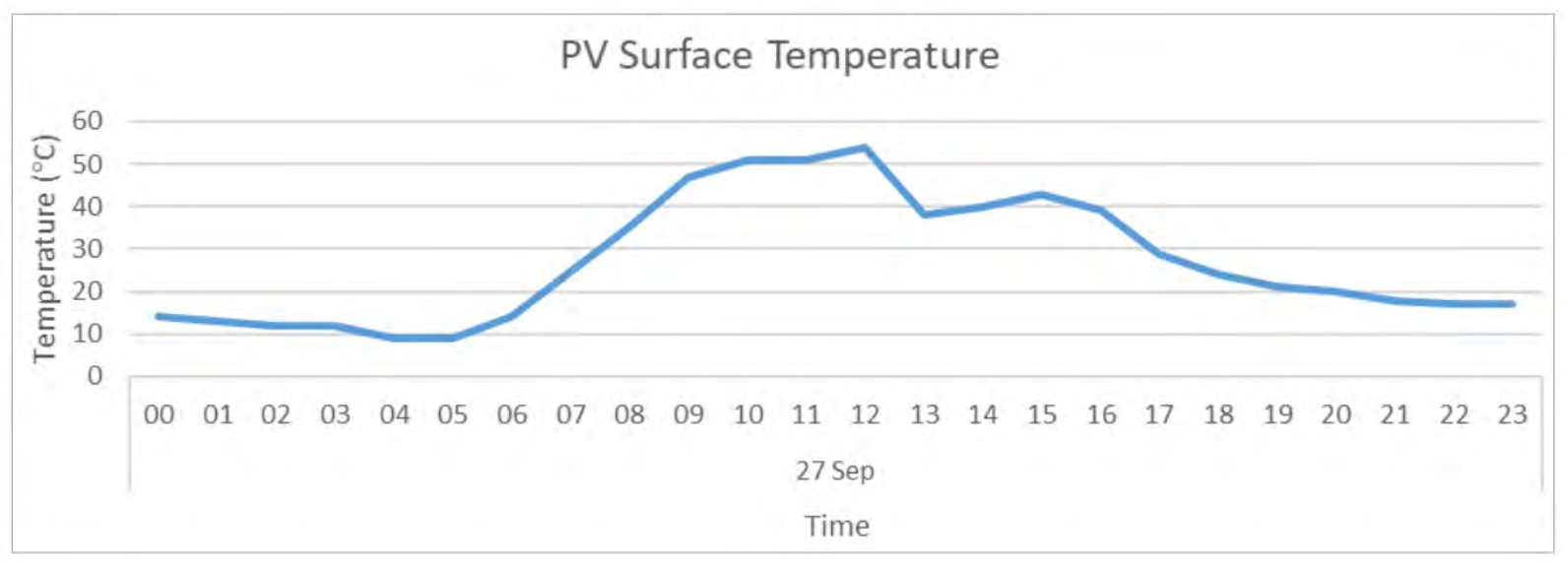

Figure 12. Hourly maximum of PV module surface temperature for 27 September 2019 (Sunny day).

Source: own elaboration. 
PV surface temperature $\left(T_{P V}\right)$ data from the DHT11 sensor is presented in Figure 13, together with the ambient temperature $\left(T_{a}\right)$ data for Bloemfontein in South Africa, obtained from timeanddate.com (Time and Date, 2020). The $T_{a}$ data available from the website is given in maximum and minimum for 00:00, 06:00, 12:00 and 18:00 for any required day. The available maximum and minimum $T_{a}$ was then captured and processed, using pivot tables where daily maximum and minimum $T_{a}$ were obtained. The $T_{P V}$ data was sampled every 100 seconds from 19 July to 16 August 2019, where the highest surface temperature was recorded to be $55^{\circ} \mathrm{C}$ on 14 August. Pivot tables were used - due to the sheer quantity of data that had to be analysed - to determine the hourly maximum and minimum $T_{P V}$ values per day, and from those a daily maximum and minimum $T_{P V}$ was derived. Results indicate that the surface temperature follows the same profile as the ambient temperature, suggesting reliability of the measurements.

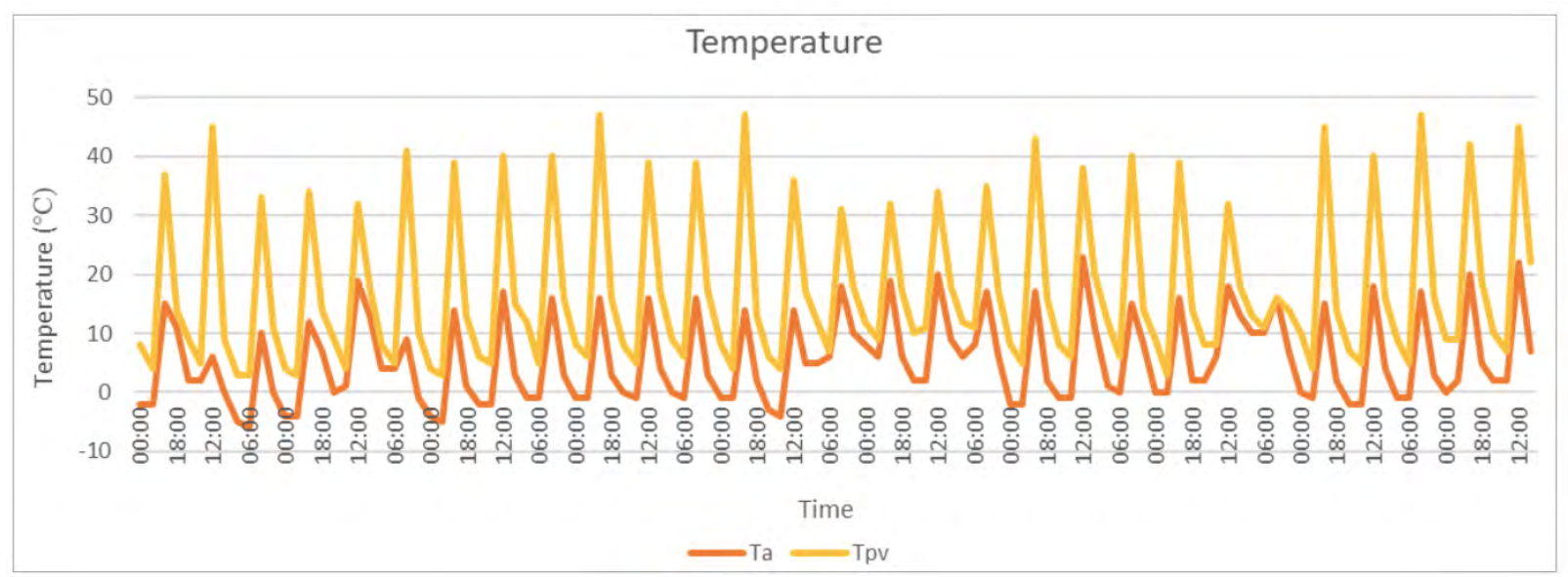

Figure 13. Ambient and PV surface temperature.

Source: own elaboration. 


\section{CONCLUSIONS}

Sensor measurements (voltage, current and temperature) were obtained from the remote ST and sent to the MT using the CG1 101 transceiver. The daily maximum of the voltage was recorded to be between 12.76 $\mathrm{V}$ and 15.44 for the said period, thereby not exceeding the rated $V_{m p}$ of $16.5 \mathrm{~V}$ for these PV modules. In addition, the PV current that was measured remotely for the same period, indicated more current for a sunny day $(2.32 \mathrm{~A})$ than a cloudy day $(1.98 \mathrm{~A})$, both which are less than the rated $I_{m p}$ of 2.44 A. These results showed a $4.9 \%$ error percentage for voltage measurements and a $3.9 \%$ error percentage for current measurements.

Temperature measurements were also taken remotely arriving at an error percentage of $0.59 \%, T_{P V}$ was observed to be significantly higher than $T_{a}$ during the day and more so around midday. An even wider gap was seen in the two parameters on a sunny day, compared to a cloudy day, whereas at night, $T_{P V}$ and $T_{a}$ were evidently similar.

The research did not focus on the different types of PV modules, actuators or solenoid valves. The inclusion of an energy regulator and storage system also did not form part of the research. This research has unfolded possibilities of future studies that could contribute to the work of maintaining optimum power of PV modules. This includes comparing the effect of cooling the PV module using a water sprayer in relation to a change in the orientation angle on the output power of the module. Incorporating cloud storage for monitoring of the output power and surface temperature from any location at any time can also be considered for further research.

\section{REFERENCES}

Allegro Microsystems. (2006). Fully Integrated, Hall Effect-Based Linear Current Sensor with 2.1 kVRMS Voltage Isolation and a Low-Resistance Current Conductor. 
Andrae, A.S., \& Edler, T. (2015). On global electricity usage of communication technology: trends to 2030. Challenges, 6(1), 117-157. https://doi.org/10.3390/challe6010117

Arduino. (2018). Arduino Mega 2560 Rev3. https://store.arduino.cc/arduino-mega-2560-rev3

Atsu, D., Seres, I., Aghaei, M., \& Farkas, I. (2020). Analysis of long-term performance and reliability of PV modules under tropical climatic conditions in sub-Saharan. Renewable Energy, 162, 285-295. https://doi.org/10.1016/j.renene.2020.08.021

Bai, A., Popp, J., Balogh, P., Gabnai, Z., Pályi, B., Farkas, I., Pintér, G., \& Zsiborács, H. (2016). Technical and economic effects of cooling of monocrystalline photovoltaic modules under Hungarian conditions. Renewable and Sustainable Energy Reviews, 60, 1086-1099. https://doi. org/10.1016/j.rser.2016.02.003

Belmili, H., Gheikh, S. M. A., Haddadi, M., \& Larbes, C. (2010). Design and development of a data acquisition system for photovoltaic modules characterization. Renewable Energy, 35(7), 14841492. https://doi.org/10.1016/j.renene.2010.01.007

Bhattacharya, T., Chakraborty, A.K., \& Pal, K. (2014). Effects of ambient temperature and wind speed on performance of monocrystalline solar photovoltaic module in Tripura, India. Fournal of Solar Energy, 2014, Article ID 817078. https://doi.org/10.1155/2014/817078

D-Robotics. (2010). DHT11 Humidity \& Temperature Sensor. https://www.circuitbasics.com/wp-content/ uploads/2015/11/DHT11-Datasheet.pdf

El Hammoumi, A., Motahhir, S., Chalh, A., El Ghzizal, A., \& Derouich, A. (2018). Low-cost virtual instrumentation of PV panel characteristics using Excel and Arduino in comparison with traditional instrumentation. Renewables: wind, water, and solar, 5(3), 1-16. https://doi.org/10.1186/ s40807-018-0049-0 
Ertekin, G., \& Yaldiz, O., (2000). Comparison of some existing models for estimating global solar radiation for Antalya (Turkey). Energy Conversion and Management, 41(4), 311-330. https://doi. org/10.1016/S0196-8904(99)00127-2

Fuentes, M., Vivar, M., Burgos, J. M., Aguilera, J., \& Vacas, J. A. (2014). Design of an accurate, low-cost autonomous data logger for PV system monitoring using Arduino that complies wih OEG standards. Solar Energy Materials \& Solar Cells, (130), 529. https:// librarysearch.rgu.ac.uk/discovery/fulldisplay?docid=cdi_gale_infotracacademiconefile_ A522384896\&context=PG\&vid=44RGU_INST:VU1\&lang=en\&search_scope=MyInst_and_ CI\&adaptor $=$ Primo $\% 20$ Central\&tab $=$ Everything\&query $=$ sub,exact, $\% 20 I$ EC $\% 20$ standards

Gay, W. (2018). DHT11 Sensor. Advanced Raspberry Pi. Springer, pp. 399-418.

Kama, A., Diallo, M., Drame, M.S., Ndiaye, M.L., Ndiaye, A., \& Ndiaye, P.A. (2017). Monitoring the performance of solar street lights in sahelian environment: Case study of Senegal. In 2017 10th International Conference on Developments in eSystems Engineering (DeSE), IEEE, pp. 56-61.

Kekre, A., \& Gawre, S.K. (2017). Solar photovoltaic remote monitoring system using IOT. In 2017 International Conference on Recent Innovations in Signal processing and Embedded Systems (RISE), 2017, pp. 619-623. https://doi.org/10.1109/RISE.2017.8378227

Koutitas, G., \& Demestichas, P. (2010). A review of energy efficiency in telecommunication networks. Telfor journal, 2(1), 2-7. https://journal.telfor.rs/Published/Vol2No1/Vol2No1_A1.pdf

Liu, J., Fang, W., Zhang, X., \& Yang, G. (2015). An improved photovoltaic power forecasting model with the assistance of aerosol index data. IEEE Transactions on Sustainable Energy, 6(2), 434-442. https:/ /ieeexplore.ieee.org/document/7029108

Nedelchev, I., \& Zhivomirov, H. (2020). A combined approach for assessment the functionality of photovoltaic modules in real-world operation. In E3S Web of Conferences 2020, EDP Sciences, pp. 02006. https://doi.org/10.1051/e3sconf/202018002006 
Ortega, E., Aranguren, G., Saenz, M. J., Gutierrez, R., \& Jimeno, J. G. (2018). Photovoltaic Module to Module Monitoring System. In 2018 IEEE 7th World Conference on Photovoltaic Energy Conversion (WCPEC) (A Joint Conference of 45th IEEE PVSG, 28th PVSEG \& 34th EU PVSEG) 2018, pp. 2703-2708.

Peng, Z., Herfatmanesh, M.R., \& Liu, Y. (2017). Cooled solar PV panels for output energy efficiency optimisation. Energy conversion and management, 150, 949-955. https://core.ac.uk/download/ pdf/161941461.pdf

Prieto, M.J., Pernía, A.M., Nuño, F., Díaz, J., \& Villegas, P.J. (2014). Development of a wireless sensor network for individual monitoring of panels in a photovoltaic plant. Sensors (Basel, Sreitzerland), 14(2), 2379-2396. https://doi.org/10.3390/s140202379

Randhir, M., \& Karhe, R.R. (2015). Monitoring Of Environmental Parameters by Using Gloud Computing. International Fournal of Computer Science Trends and Technology (IFCST), 3(3), 151-155. http:/ / www.ijcstjournal.org/volume-3/issue-3/IJCST-V3I3P27.pdf

Rasberry Pi. (2018). Rasberry Pi 3 model b+. https://www.raspberrypi.org/products/raspberry-pi-3model-b-plus/

Schwingsshack1, G., Petitta, M., Wagner,J.E., Belluardo, G., Moser, D., Castelli, M., Zebisch, M., \& Tetzlaff, A. (2013). Wind effect on PV module temperature: Analysis of different techniques for an accurate estimation. Energy Procedia, 40, 77-86. https://doi.org/10.1016/j. egypro.2013.08.010

Spagnuolo, A., Petraglia, A., Vetromile, C., Formosi, R., \& Lubritto, G. (2015). Monitoring and optimization of energy consumption of base transceiver stations. Energy, 81, 286-293. https:// ideas.repec.org/a/eee/energy/v81y2015icp286-293.html 
Swapnil, D., Jatin, S., \& Bharath, S. (2013). Temperature Dependent Photovoltaic (PV) Efficiency and Its Effect on PV Production in the World - A Review. Energy Procedia, 33, 311-321. https:// doi.org/10.1016/j.egypro.2013.05.072

Telkom, S.A. (2018). 2018 Telkom sa integrated report. http://telkom-reports.co.za/reports/ar-2018/pdf/ full-integrated.pdf

Texas Instruments. (2018). CC1101 Low-Power Sub-1 GHz RF Transceiver. http://www.ti.com/lit/ds/ symlink/cc1101.pdf

Time and Date. (2020). 2020-last update. Fuly 2019 Weather in Bloemfontein - Graph. https://www. timeanddate.com/weather/south-africa/bloemfontein/historic? $\mathrm{month}=7$ \&year=2019

Tina, G.M., \& Grasso, A.D. (2014). Remote monitoring system for stand-alone photovoltaic power plants: The case study of a PV-powered outdoor refrigerator. Energy Conversion and Management, 78, 862-871. https://doi.org/10.1016/j.enconman.2013.08.065 